\title{
Opposite long-term trends in aerosols between low and high altitudes: a testimony to the aerosol-PBL feedback
}

\author{
Zipeng Dong ${ }^{1,2}$, Zhanqing $\mathbf{L i}^{1,3}$, Xing $\mathbf{Y u}^{2}$, Maureen $\mathrm{Cribb}^{3}$, Xingmin $\mathbf{L i}^{2}$, and Jin $\mathrm{Dai}^{2}$ \\ ${ }^{1}$ State Key Laboratory of Earth Surface Processes and Resource Ecology and College of Global Change and Earth System \\ Science, Beijing Normal University, Beijing, 100875, China \\ ${ }^{2}$ Meteorological Institute of Shaanxi Province, Xi'an, 710014, China \\ ${ }^{3}$ Department of Atmospheric and Oceanic Science, University of Maryland, College Park, MD 20742, USA
}

Correspondence to: Zhanqing Li (zli@atmos.umd.edu)

Received: 1 January 2017 - Discussion started: 3 January 2017

Revised: 1 June 2017 - Accepted: 2 June 2017 - Published: 30 June 2017

\begin{abstract}
Interactions between absorbing aerosols and the planetary boundary layer (PBL) play an important role in affecting air pollution near the surface. In this study, a unique feature of the aerosol-PBL interaction is identified that has important implications in monitoring and combating air pollution. Opposite trends in aerosol loading between the lower and upper PBL are shown on a wide range of timescales and data acquired by various platforms: from a short-term field experiment to decadal satellite observations and multidecadal ground observations in China. A novel method is proposed to obtain the vertical profiles of aerosol loading from passive sensors by virtue of varying elevations. The analyses of visibility, aerosol optical depth, and extinction with different temporal scales exhibit the similar trend, i.e., increasing in the lower atmosphere but decreasing in the upper atmosphere. Integration of the reversal aerosol trend below and above the PBL resulted in a much less change in the column-integrated quantities. The surface cooling effect, together with the change in the heating rate induced by the absorbing aerosol, unevenly modifies the atmospheric temperature profile, causing a more stable atmosphere inside the PBL but a destabilized atmosphere above the PBL. Such a change in the atmospheric stability favors the accumulation of pollutants near the surface and the vertical diffusion of aerosol particles in the upper atmosphere, both of which are consistent with the observed reversal aerosol trends. These findings have multiple implications in understanding and combating air pollution, especially in many developing countries with high emissions of light-absorbing aerosols.
\end{abstract}

\section{Introduction}

Air pollution induced by rapid industrialization and urbanization over the past decades has become a critical constraint for sustainable development in China. The frequent occurrence of hazy weather has severely undermined people's lives. Long-term exposure to ambient particulate matter (PM) may have led to significant increases in cardiorespiratory mortality in China (Chen et al., 2013; Yin et al., 2015). The PM, or aerosols in general, can also alter weather and climate due to their radiative and microphysical effects, especially in regions with high aerosol loading such as Asia.

Average concentrations of $\mathrm{PM}$ with aerodynamic diameters $<10 \mu \mathrm{m}\left(\mathrm{PM}_{10}\right)$ and $<2.5 \mu \mathrm{m}\left(\mathrm{PM}_{2.5}\right)$ at urban/suburban sites in China from 2006 to 2014 are 83.6 and $56.3 \mu \mathrm{g} \mathrm{m}^{-3}$, respectively, while values at rural stations are 54.8 and $30.8 \mu \mathrm{g} \mathrm{m}^{-3}$, respectively (Y. Q. Wang et al., 2015). Mean ground-level $\mathrm{PM}_{2.5}$ concentrations observed over the North China Plain and the Guanzhong Plain (GZP) exceed the latest air quality standards of China by several times (Y. Q. Wang et al., 2015). The mean aerosol optical depth (AOD) observed by sun photometers in rural and urban sites over China was 0.34 and 0.74, respectively (Lee et al., 2007; Che et al., 2015), which is well above the global average of 0.17 (Lee and Chung, 2013). Heavy aerosol loading over China as revealed by both ground and satellite observations has a significant influence on a wide range of meteorological variables and may play significant roles in the climate change of China (Wu et al., 2016) and the Asian monsoon system ( $\mathrm{Li}$ et al., 2016). 
Economic development plays an important role in dictating air quality in China. The spatial and temporal distributions of AOD and $\mathrm{PM}_{2.5}$ are also affected by urbanization and topography (Li and Wang, 2014). Through the study of extreme air pollution events, the interaction between absorbing aerosols and the planetary boundary layer (PBL) height (PBLH) was recognized as an important contributor to the accumulation of PM in the near-surface atmosphere over China (Wendisch et al., 2008; Ding et al., 2013). Together with fossil fuel combustion, biomass burning is the main source releasing absorbing aerosols into the atmosphere. It has been demonstrated that regional haze development in China is dominated by the secondary formation processes (Guo et al., 2014; Zhang et al., 2015; Wang et al., 2016), which likely considerably enhances the optical properties of black carbon particles (R. Y. Zhang et al., 2008; Khalizov et al., 2009; Peng et al., 2016). Besides the urban/industrial pollution, Y. Zhang et al. (2008) and Tesfaye et al. (2014) demonstrated that the biomass burning aerosols also have an important impact on the evolution of PBL. A broad theoretical perspective of the impact of absorbing aerosols on the PBL was hypothesized by Wang et al. (2013), suggesting that a feedback between the PBLH and absorbing aerosols may play a key role in the aggravation of surface pollution during heavy pollution episodes. Through scattering and absorption of solar radiation, atmospheric aerosols reduce net surface shortwave radiation (SSR) and thus induce surface cooling. The decreased net SSR reduces sensible heat fluxes (Y. Zhang et al., 2008), which leads to weakened surface buoyancy fluxes (Tesfaye et al., 2014). Moreover, black carbon aerosols absorb solar radiation in the visible wavelengths and consequently warm up and stabilize the atmosphere. The changes in atmospheric radiative heating rate and atmospheric stability depend on the vertical distribution of aerosols (Gonçalves et al., 2015). If the absorbing aerosols are confined to the top of the PBL, they may incur or strengthen a temperature inversion below the entrainment zone, leading to the suppression of vertical motion and to a shallower PBL (Barbaro et al., 2013). This creates unfavorable atmospheric conditions for pollution dispersion and thus worsens surface air pollution. This mechanism was demonstrated clearly in a recent modeling study by Ding et al. (2016). They showed that the aerosol-PBL feedback tends to increase lower PBL pollution and decrease upper PBL pollution.

In this study, we strive to obtain unique observational evidence that the aerosol-PBL feedback plays a special role in the long-term trend in air pollution, especially at the ground level, using both ground-based and historical satellite measurements.

\section{Data}

We used three types of measurements: long-term surface visibility measurements, medium-term satellite retrievals, and short-term field experiment measurements to take advantage of the merits of each product.

Visibility data obtained by China Meteorological Administration (CMA) stations located on the GZP are used here as a proxy for air quality at the surface, while AODs retrieved from the Moderate-Resolution Imaging Spectroradiometer (MODIS) and the Multi-angle Imaging SpectroRadiometer (MISR) are used to denote total aerosol loading in the atmospheric column. Operational MODIS level 2 aerosol products with a spatial resolution of $10 \mathrm{~km}$ at nadir and MISR level 2 aerosol products with a spatial resolution of $17.6 \mathrm{~km}$ were used to generate gridded AOD data at every $0.1^{\circ} \times 0.1^{\circ}$ latitude-longitude pair and $0.2^{\circ} \times 0.2^{\circ}$ latitudelongitude pair over China, respectively.

The GZP is a key economic zone in western-central China, located along the lower valley of the Wei River (Fig. 1a). As one of the most densely populated regions of China, the GZP covers an area of $34000 \mathrm{~km}^{2}$ and has a population of about 25 million people. The average altitude of the plain is around $500 \mathrm{~m}$. Xi' an is the largest and most developed city in the plain. As shown in Fig. 1, the spatial distribution of AOD follows the topography closely, i.e., higher over the basin than over the surrounding hilly mountain area.

The Qinling Atmospheric Environment Observation Experiment was conducted at the Chang'an meteorological station in the southern suburb of Xi' an $\left(34.150^{\circ} \mathrm{N}, 108.917^{\circ} \mathrm{E}\right.$; 433 ma.s.l., above sea level) and at the nearby Qinling Mountains. Measurements of aerosols and atmospheric radiation have been made since May 2013 at Chang'an. Its goal is to investigate the impact of heavy aerosol loading on radiation, clouds, and climate in central China. A multi-filter rotating shadowband radiometer (MFRSR) and a set of broadband radiometers were operated side by side. A micro-pulse lidar (MPL) manufactured by the Sigma Space Corporation was used to obtain aerosol profiles. Based on solar radiation measurements from the MFRSR, the Langley technique was used to retrieve AODs in the visible and near-infrared spectral bands.

The focus of our work is the trend in aerosols and the aerosol-PBL feedback under clear-sky conditions, so the first step is to discriminate between clear and cloudy/foggy conditions. A threshold of $90 \%$ in relative humidity (RH) is widely used to distinguish between haze $(\mathrm{RH}<90 \%)$ and fog ( $\mathrm{RH}>90 \%)$ in visibility datasets (Chen and Wang, 2015). However, Ding and Liu (2014) suggested that a value of $\sim 82 \%$ may be more suitable for differentiating between haze and fog over China. We use an intermediate value of $85 \%$ in our study. For AOD and aerosol extinction profile retrievals from the MFRSR and the MPL, the automated cloud identification algorithm proposed by Alexandrov et al. (2004) was used to screen out cloud-contaminated data. Cloud-free AOD retrievals from the MFRSR are subsequently used to constrain MPL-derived aerosol extinction coefficient profiles according to Welton et al. (2000). It is important to assure that there are no clouds along the pathway 

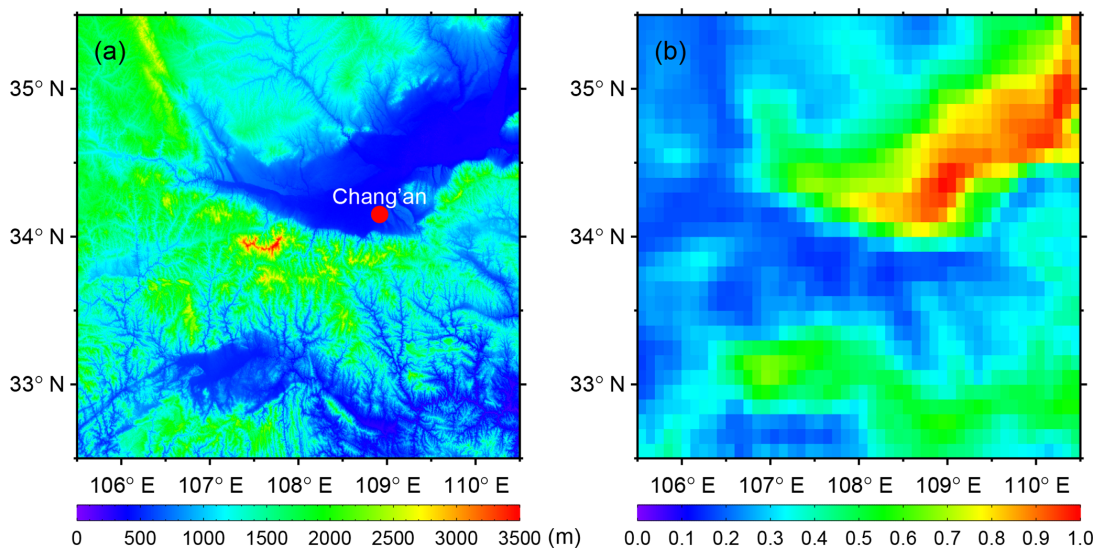

Figure 1. (a) A topographic map of the Guanzhong Plain and (b) the spatial distribution of AOD over the region shown in (a). The red solid dot in (a) shows the location of the Qinling experimental site in Chang'an near Xi'an.

of the MPL laser beam when obtaining vertically integrated aerosol extinction coefficients from the MPL. The columnintegrated AOD from the MPL and the AOD retrieved from the MFRSR should be consistent.

\section{Trend analyses}

\subsection{Trends in visibility and AOD}

The very rapid urbanization and economic development in China from the 1980s until the present has resulted in serious pollution problems in this region, as shown by the trend in visibility measurements made at stations located at altitudes less than $1 \mathrm{~km}$ (Fig. 2a). Note that the two are anticorrelated: poor visibility corresponds to high AOD (Fig. 2b). From 1980 to about 2008, visibility over the lowland of the GZP had been declining. A turnaround has occurred since then with a more dramatic improvement in visibility occurring over the past few years when Chinese central and local governments began to take action toward curbing air pollution. This increase in visibility was accompanied by a decrease in AOD, which is seen in both ground and satellite observations. However, a different trend in visibility measured at the high mountain stations (altitudes over $1 \mathrm{~km}$ ) is seen, i.e., a general increasing trend since 1980, suggesting that air quality over the mountains has been improving.

Note that visibility is often influenced by local emissions and fog whose long-term trends may contribute to visibility trends. To overcome this limitation, we also analyzed trends in AOD clustered according to topography so that each set of AODs represents the aerosol loading at some level above ground. By varying the ground elevation, we can derive profiles of AOD trends at different altitudes as shown in Fig. 3 using both MODIS and MISR data. AOD retrievals from both satellite products show that the trend in AOD varies with height, i.e., increasing at low altitudes but decreasing at higher altitudes. We hypothesize that this switch in trend with height results from the feedback between absorbing aerosols and the PBLH. The difference in the spatial sampling and spatial resolution of the two instruments may explain why MISR AOD trend values are smaller than those from MODIS. As shown in Figs. 4 and 5a, b, the variation in AOD (or aerosol extinction coefficient) with altitude is more dramatic at low altitudes than at high altitudes. As a result, when AOD retrievals are averaged onto grids over undulating areas at different altitudes, the AOD, as well as the AOD trend, within the grid boxes at low altitudes will be smoothed out. To further investigate this, MODIS level 2 aerosol products were averaged onto $0.2^{\circ} \times 0.2^{\circ}$ latitudelongitude grids in the same manner as the MISR aerosol products. Comparisons between MODIS AOD trend profiles for different grid sizes (i.e., $0.1^{\circ} \times 0.1^{\circ}$ and $0.2^{\circ} \times 0.2^{\circ}$ ) are shown in Fig. 6. There is almost no difference above $500 \mathrm{~m}$. AOD trend values below $500 \mathrm{~m}$ from the gridded data at the $0.2^{\circ} \times 0.2^{\circ}$ spatial resolution are much smaller than those at the $0.1^{\circ} \times 0.1^{\circ}$ spatial resolution, suggesting that the smoothing effect induced by a lower spatial resolution exists. Despite MODIS and MISR AOD data are averaged using the same grid size, AOD trend values from MODIS (blue dots in Fig. 6) at low altitudes being still larger than those from MISR (Fig. 3b). Zhang and Reid (2010) demonstrated that even if MODIS and MISR AOD retrievals were averaged onto the same $1^{\circ} \times 1^{\circ}$ latitude-longitude grid, MISR trends were still half that of the MODIS trends due to the spatial sampling differences of the two instruments.

\subsection{Variation of the trend with height}

The proportion of light-scattering aerosol components, e.g., nitrate and sulfate, to the total $\mathrm{PM}_{2.5}$ in Xi' an is much lower than that in other big cities such as Beijing, Shanghai, and Guangzhou, while the proportion of light-absorbing aerosol components, e.g., black carbon and dust, is much higher (Huang et al., 2014). The single scattering albedo (SSA) over 

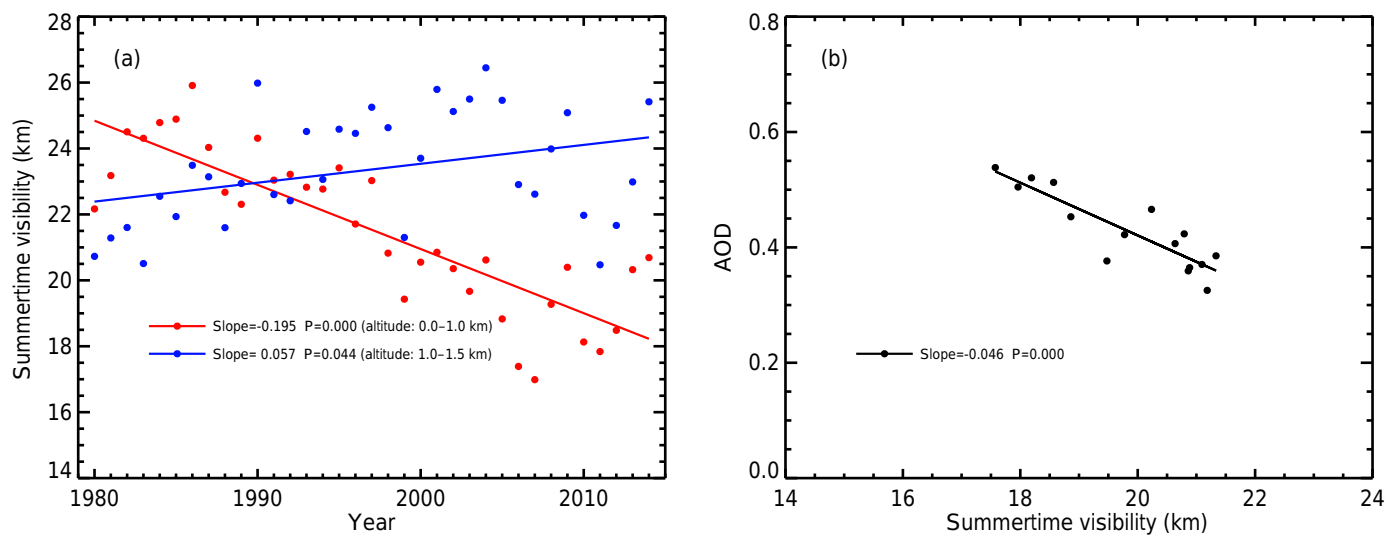

Figure 2. (a) Long-term trends in visibility measured at meteorological stations located at different altitudes on the Guanzhong Plain and in the surrounding mountain region. (b) Correlation between aerosol optical depth (AOD) and visibility over the plain.
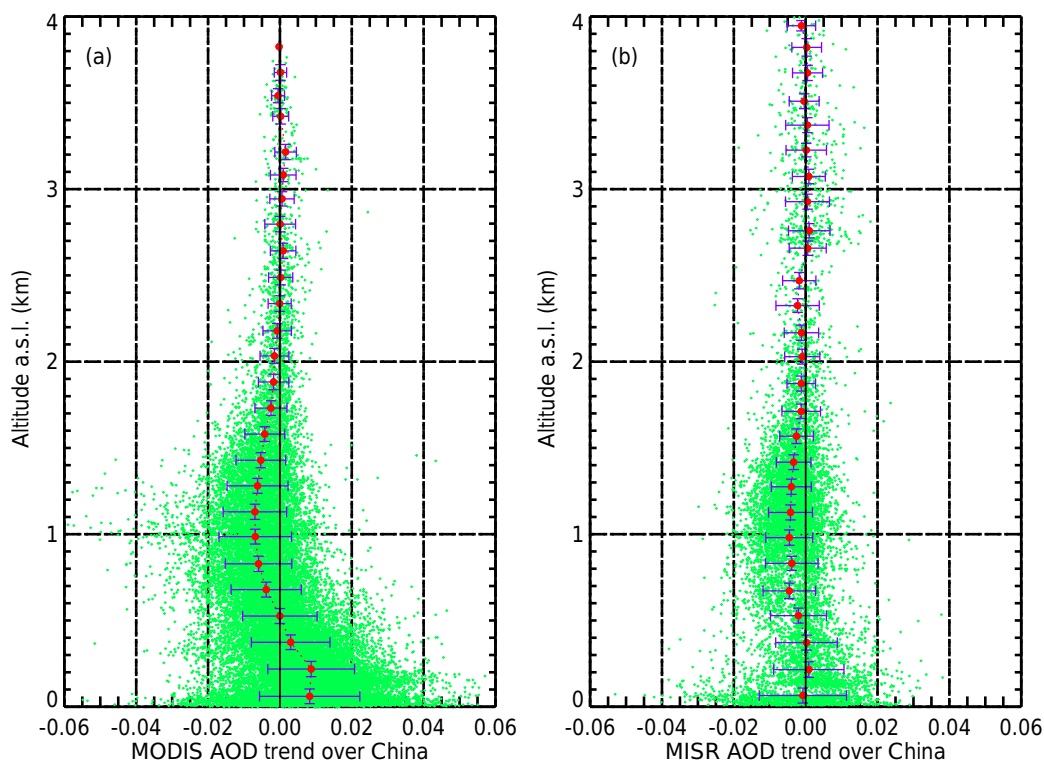

Figure 3. Vertical profiles of aerosol optical depth (AOD) trends over the entirety of China from (a) MODIS and (b) MISR retrievals in the summer seasons of 2002 to 2014. Red dots and horizontal bars represent mean tendencies and standard deviations, respectively. The "a.s.l." in the ordinate labels stands for "above sea level". The specific region of study can be found in Fig. S2 in the Supplement.

this region is well below 0.85, while the mean SSA in China is $\sim 0.9$ and high in southeast China, as derived by Lee et al. (2007) from a combination of satellite and ground observations across China. Absorbing aerosols trap solar radiation in the atmosphere with much more intensive heating in the upper PBL than in the lower atmosphere. This could lead to a significant decrease in the PBLH, which tends to increase near-surface particulate concentrations.

However, the aforementioned process is complex and difficult to evaluate by direct observations due to the influence of other factors, such as the large-scale circulation, local pollutant emissions, and atmospheric transport. Therefore, the study of the interaction between aerosols and the PBLH has thus far been mainly achieved through model simulations or by studying short-term extreme pollution cases. The complex terrain of the GZP hinders the advective diffusion of pollution (Zhao et al., 2015a) and thus provides a unique opportunity to study the interaction between aerosols and the PBLH. Here we attempt to illustrate the impact of aerosols on the evolution of the PBL and the feedback between them by using long-term observations from the GZP.

\subsubsection{Comparison of profiles of aerosol extinction from satellite and lidar}

Profiles of aerosol extinction were derived from MPL backscattering measurements in conjunction with MFRSR AOD data following the method of Welton et al. (2000). Data 

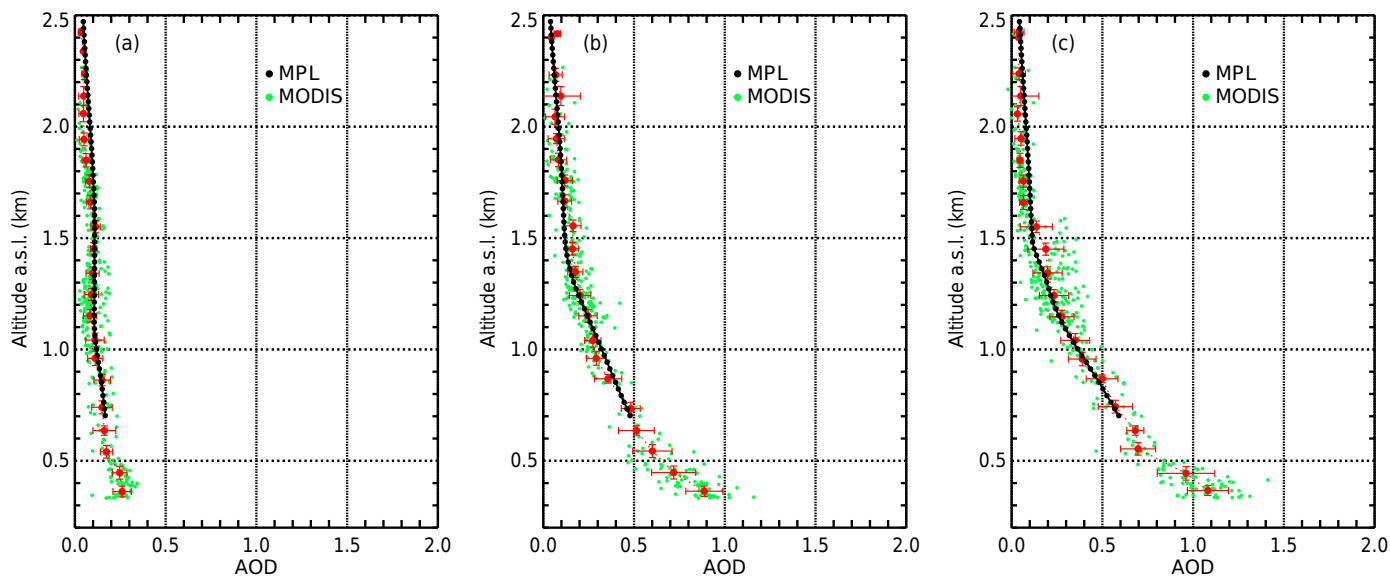

Figure 4. AOD at different altitudes derived from MODIS retrievals over the study region shown in Fig. 1a (green dots) and MPL (black dots) data on (a) 13 September 2013 at 06:00 coordinated universal time (UTC), (b) 26 March 2014 at 05:50 UTC, and (c) 29 September 2013 at 06:00 UTC. Red dots and horizontal bars represent mean MODIS AODs and standard deviations, respectively. Only those MODIS 5 min granules with a sufficient amount of valid AOD data ( $>75 \%)$ are chosen.

collected at the Chang'an station during the summers of 2013 and 2014 were used in this study to characterize the aerosol vertical distribution.

Due to a lack of long-term MPL observations, we propose a novel approach of obtaining profiles of aerosol extinction from AOD measurements at different altitudes by assuming that aerosols are homogeneously distributed across the basin surrounded by the Qinling Mountains and the Loess Plateau. Data from the summers of 2002-2014 extracted from the Collection 6 MODIS-Aqua AOD product are used. Unlike other plains, the GZP is rarely influenced by large-scale circulations because airflow is blocked by the $1500 \mathrm{~km}$ long Qinling mountain range. Also, the regional prevailing winds over the GZP are unfavorable for the horizontal transport of PM (Zhao et al., 2015b). As a result, particles are mostly confined to their source region and tend to accumulate in the lowlands (Zhao et al., 2015a). In this case, aerosols may be well-mixed over the valley. The AOD at a given location and at an elevation of $z$ (in meters), denoted as $\mathrm{AOD}_{z}$, is defined as the integrated extinction coefficient over the vertical path from the surface to the top of atmosphere (TOA):

$\mathrm{AOD}_{z}=\int_{z}^{\mathrm{TOA}} \beta_{z^{\prime}} \mathrm{d} z^{\prime}$,

where $\beta_{Z^{\prime}}$ is the extinction coefficient at a height of $z^{\prime}$.

If the hypothesis is true, the observed AODs at the same elevation over the GZP should be similar. To test this, comparisons were made between the MODIS AOD at different altitudes and the integrated extinction coefficient obtained from the MPL. As shown in Fig. 4, the AOD at different altitudes (green dots) and MPL data (black dots) are generally consistent. Note that the MPL detects vertical profiles of aerosols directly above the observation site in the GZP, while MODIS AOD retrievals are spatially distributed over the rugged terrain surrounding the plain. The distance between MODIS AOD pixels at varying altitudes and the MPL site at the Chang'an station increases with altitude. Consequently, profiles derived from MODIS AOD at different locations having different altitudes represent basin-wide (including the perimeters of the surrounding mountains) profiles. Profiles from the MPL were obtained at a fixed site. As such, the agreement between the AODs at varying altitudes from the MPL and MODIS attests to the validity of our assumption that the vertical mixing is uniform across the basin.

Thus, AOD with respect to any vertical path segment going from $z_{0}$ to $z_{1}$, denoted as $\mathrm{AOD}_{z_{0}-z_{1}}$, can be computed by integrating the extinction coefficient $\beta_{Z^{\prime}}$ over the corresponding altitude range or by subtracting the AOD observed at $z_{0}$ from that observed at $z_{1}$ :

$$
\begin{aligned}
\operatorname{AOD}_{z_{0}-z_{1}} & =\int_{z_{0}}^{z_{1}} \beta_{z^{\prime}} \mathrm{d} z^{\prime}=\int_{z_{0}}^{\mathrm{TOA}} \beta_{z^{\prime}} \mathrm{d} z^{\prime}-\int_{z_{1}}^{\mathrm{TOA}} \beta_{z^{\prime}} \mathrm{d} z^{\prime} \\
& =\mathrm{AOD}_{z_{0}}-\mathrm{AOD}_{z_{1}} .
\end{aligned}
$$

In this way, any portion of AOD at a given altitude range can be obtained from a combination of MODIS AOD data and Advanced Spaceborne Thermal Emission and Reflection Radiometer (ASTER) global digital elevation model (GDEM) standard data products at a $30 \mathrm{~m}$ spatial resolution (http://reverb.echo.nasa.gov/reverb). Gridded mean summertime AODs for the period 2002-2014 are first created by gridding the high-quality (quality assurance confidence flag of 3) granule-level MODIS AOD retrievals onto a daily $0.1^{\circ}$ longitude $\times 0.1^{\circ}$-latitude grid. The mean AOD is then calculated by averaging the daily AODs in each grid box. Grid boxes over the GZP containing elevations from the GDEM with high relative standard deviations $(>10 \%)$ are not in- 

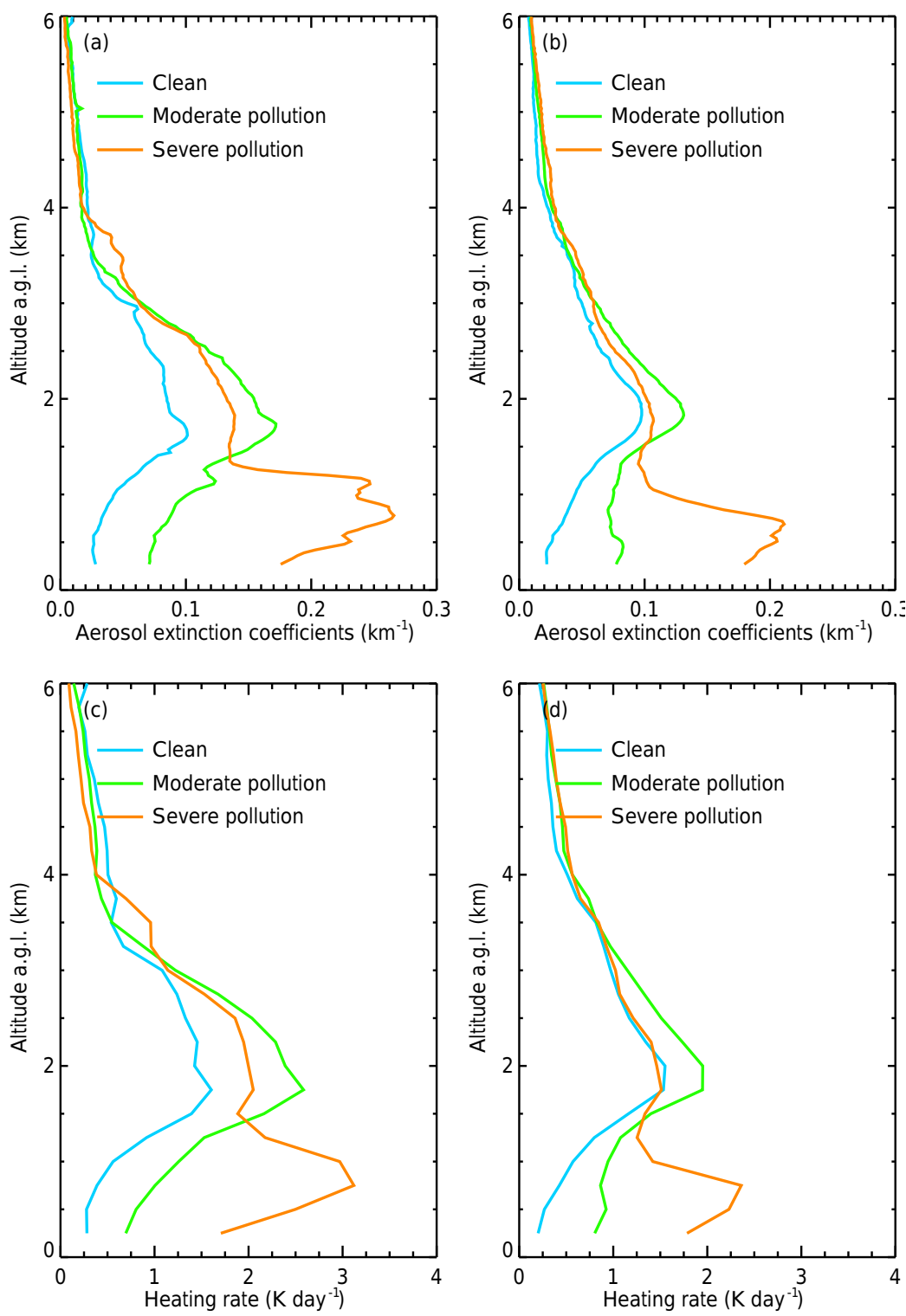

Figure 5. Mean summertime aerosol extinction profiles measured by the MPL in (a) 2013 and (b) 2014 and summertime atmospheric heating rates induced by aerosols in (c) 2013 and (d) 2014. Profiles representing relatively clean, moderate pollution, and severe pollution scenarios are shown as blue, green, and yellow lines, respectively. The "a.g.l." in the ordinate labels stands for "above ground level".

cluded in the analysis because the AOD in those boxes can vary considerably due to the elevation inhomogeneity.

To illustrate the impact of aerosols on the vertical temperature structure, the Santa Barbara DISORT Atmospheric Radiative Transfer (SBDART) model (Ricchiazzi et al., 1998) was used in this study to simulate the atmospheric heating rate induced by absorbing aerosols. The aerosol inputs to the SBDART model are AODs, Angström exponents retrieved from MFRSR measurements, SSAs (i.e., 0.84 and 0.80 at 470 and $660 \mathrm{~nm}$, respectively) taken from Lee et al. (2007), and aerosol extinction profiles at $532 \mathrm{~nm}$ obtained from the MPL. The mid-latitude summer atmospheric profile adopted in the SBDART model was used in simula- tions. Additional input parameters include MODIS surface reflectance (https://reverb.echo.nasa.gov/reverb/), ozone column amounts from the Ozone Monitoring Instrument (https: //ozoneaq.gsfc.nasa.gov/data/ozone/), and precipitable water vapor from the MFRSR.

\subsubsection{Coupling between the PBL and aerosol absorption}

The aerosol extinction profiles obtained from co-located MFRSR and MPL measurements were classified into three categories based on the quartiles of the aerosol loading in the lowest $270-870 \mathrm{~m}$ of the atmosphere: 


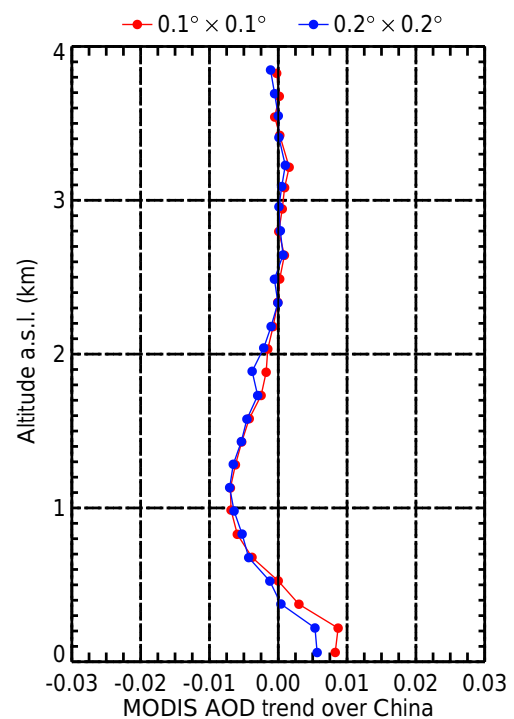

Figure 6. Vertical profiles of aerosol optical depth (AOD) trends over the entirety of China from gridded MODIS AOD data at $0.1^{\circ} \times 0.1^{\circ}$ (red dots and red line) and $0.2^{\circ} \times 0.2^{\circ}$ (blue dots and blue line) spatial resolutions from 2002 to 2014 .

1. clean condition in the first quartile;

2. moderate pollution between the second and third quartile;

3. severe pollution in the fourth quartile.

An altitude of $270 \mathrm{~m}$ was chosen as the lower limit because of missing data in the blind zone of the MPL (0-270 m). The upper limit of $870 \mathrm{~m}$ is a value established by Song et al. (2013) who found that $\sim 50 \%$ of aerosols were confined to the lowest $600 \mathrm{~m}$ of the atmosphere over Lanzhou, a city surrounded by mountains.

Aerosol profiles corresponding to the three pollution levels in the summers of 2013 and 2014 are shown in Fig. 5a and $b$. The column-integrated AODs for the clean, moderate pollution, and severe pollution categories are $0.23,0.38$, and 0.50 in Fig. 5a and 0.24, 0.33, and 0.41 in Fig. 5b, respectively. The PBLH for the clean, moderate, and severe pollution cases are, respectively, 2.9, 2.4, and $1.2 \mathrm{~km}$ in the summer of 2013 and 2.2, 2.0, and $0.8 \mathrm{~km}$ in the summer of 2014 . As shown in Fig. 5a and b, the shapes of the aerosol profiles under each pollution condition in both years are similar, suggesting that these profiles are characteristic of the region. The relative changes in the level of pollution in the lower and upper PBL are generally out of phase. For the case of severe pollution (orange curve), pollution decreases most dramatically at the top of a presumably shallow PBL, whereas extinction increases with height for the clean and moderate pollution cases. Extinction coefficients above $1500 \mathrm{~m}$ for the severe pollution case are smaller than those in the moderate pollution case. Our finding suggests that a strong correlation exists between absorbing aerosols and the PBL over the GZP. However, causality cannot be established by such an analysis because the PBL strongly affects aerosols and vice versa.

Several simulation studies have demonstrated the coupling between absorbing aerosols and the PBL in China. Absorbing aerosols heat up the lower atmosphere due to aerosol absorption of solar radiation and cool down the lower PBL by reducing the amount of solar radiation reaching the earth's surface (Wendisch et al., 2008; Ding et al., 2013). Thus, aerosols trapped in the basin increase atmospheric stability and suppress convection locally (Fan et al., 2015). Ding et al. (2016) found that the $\mathrm{PM}_{2.5}$ mass concentration was significantly underestimated near the surface and overestimated around the top of the PBL when the impact of absorbing aerosols was neglected. Furthermore, aerosols have been closely linked with modification of cloud systems of various scales due to their direct and indirect effects. It has been clearly shown that long-term cloud properties and precipitation have been significantly modified by highly elevated aerosols in China, as evident by suppressed light rainfall but intensified heavy rainfall over the Pearl River Delta megacity area (Wang et al., 2011). Owing to the enhanced surface cooling and atmospheric heating caused by aerosol radiative effect, strong absorbing aerosols may lead to decreased cloud fraction and precipitation for the deep convective clouds (Fan et al., 2008). In addition, high aerosol concentrations tend to increase precipitation associated with the mesoscale convective system but decrease the summertime local-scale precipitation (Wang et al., 2011; Guo et al., 2017).

The PBLH is found to be highly depended on the magnitude of solar radiation received at the surface. The development of PBL will be suppressed when less solar radiation reaches the surface (Guo et al., 2016). On a national average, the aerosol direct radiative forcing (ADRF) at the surface $\left(-15.7 \mathrm{~W} \mathrm{~m}^{-2}\right)$ and within the atmospheric column $\left(16.0 \mathrm{~W} \mathrm{~m}^{-2}\right)$ are exceptionally large but of opposite signs in China, suggesting that aerosols in China substantially reduce solar radiation reaching the ground and warm up the atmosphere (Li et al., 2010). The parameterization schemes developed by Xia et al. (2007) were used to quantitatively estimate aerosol-induced changes in the net SSR, namely the ADRF at the surface, at $\mathrm{Xi}$ 'an by using the AOD retrievals from the MFRSR, the MODIS surface albedo products (MCD43B3), and the global shortwave radiation (SWR) measured by Kipp \& Zonen CMP21 from June 2013 to August 2014. The diurnal variation of the ADRF in summer at $\mathrm{Xi}$ 'an is shown in Fig. S1. The mean diurnal ADRF is $-35.7 \mathrm{~W} \mathrm{~m}^{-2}$ for the global SWR at the surface in summer. Additionally, the ADRF during the daytime showed very large negative values, implying weakened surface buoyancy fluxes and decreased PBLH (Y. Zhang et al., 2008; Tesfaye et al., 2014).

Aerosol heating rates computed during the course of the day (08:00-18:00 China Standard Time) in the summer are shown in Fig. 5c and d. The maximum heating rate occurs at $\sim 1 \mathrm{~km}$ under severe pollution condition. In the relatively 
clean and moderate pollution scenarios, maximum heating rates are seen at higher altitudes. This suggests that the stability inside the PBL was strengthened while the instability above the PBL was enhanced, causing a "heat pump" effect (Lau and Kim, 2006) that favors the vertical diffusion of aerosol particles in the upper atmosphere. As a result, aerosol extinction coefficients observed at altitudes above $1500 \mathrm{~m}$ in the most polluted scenario are lower than in the moderately polluted scenario.

The visibility at ground level has significantly decreased in northern China from 2000 to 2012 (Chen and Wang, 2015) and the number of hazy days has increased noticeably (H. J. Wang et al., 2015). However, the column-integrated AOD has shown a much weaker trend as shown in Fig. 3 and in Lin et al. (2013). The disproportionate changes in surface visibility and column aerosol loading could be due to the rapid accumulation of particles near the surface in combination with a reduction in aerosol particles in the upper PBL due to the inefficient vertical transport of aerosol particles.

To test this conjecture, we used the MODIS AOD product to derive aerosol loading in the lower PBL (400$\left.800 \mathrm{~m}, \mathrm{AOD}_{400-800 \mathrm{~m}}\right)$ and the upper PBL $(1500-1900 \mathrm{~m}$, $\mathrm{AOD}_{1500-1900 \mathrm{~m}}$ ) using the aforementioned method for each summer from 2002 to 2014 . The aerosol scale height was calculated using an exponential curve fitting of MODIS AOD and ASTER GDEM data (Dong et al., 2013). The aerosol scale height is used as a proxy of the PBLH because it is related to the height of the boundary layer (Gerasopoulos et al., 2003). The scatterplots of $A_{O D} 400-800 \mathrm{~m}$ and $A D_{1500-1900 m}$ as a function of aerosol scale height in Fig. 7 shows the difference in the response of the aerosol loading at different altitudes to the scale height. As the AOD near the surface increases from 0.2 to 0.6 , the aerosol scale height drops from $\sim 1100$ to $670 \mathrm{~m}$. In response to the decrease in scale height, the aerosol loading above the PBL decreases. The correlation coefficients of the linear relationships between $\mathrm{AOD}_{400-800 \mathrm{~m}}$ and $\mathrm{AOD}_{1500-1900 \mathrm{~m}}$ and the aerosol scale height are 0.71 and 0.55 , respectively. The correlations are statistically significant at the $95 \%$ confidence level. However, the correlation coefficient of the linear relationship between $\mathrm{AOD}_{1500-1900 \mathrm{~m}}$ and $\mathrm{AOD}_{400-800 \mathrm{~m}}$ does not reach the 0.05 significance level, suggesting that the amount of aerosol particles near the surface has an indirect impact on the aerosol concentration in the upper PBL through its effect on the PBLH.

During the period of MODIS observations, the trend in AOD over China has a turning point around 2008: an upward trend pre-2008 followed by a downward trend post2008, as reported by He et al. (2016). We examined the summertime trends in AOD at different altitudes during the periods 2002-2008 (red line in Fig. 8a) and 2008-2014 (blue line in Fig. 8a). AOD over the lowlands $(<800 \mathrm{~m})$ increased dramatically during the period 2002-2008. However, the AOD at higher altitudes $(1.7-2.3 \mathrm{~km})$ decreased at a rate of -0.0075 per year. It is worth emphasizing that the magnitude of this negative AOD tendency at high altitudes exceeds

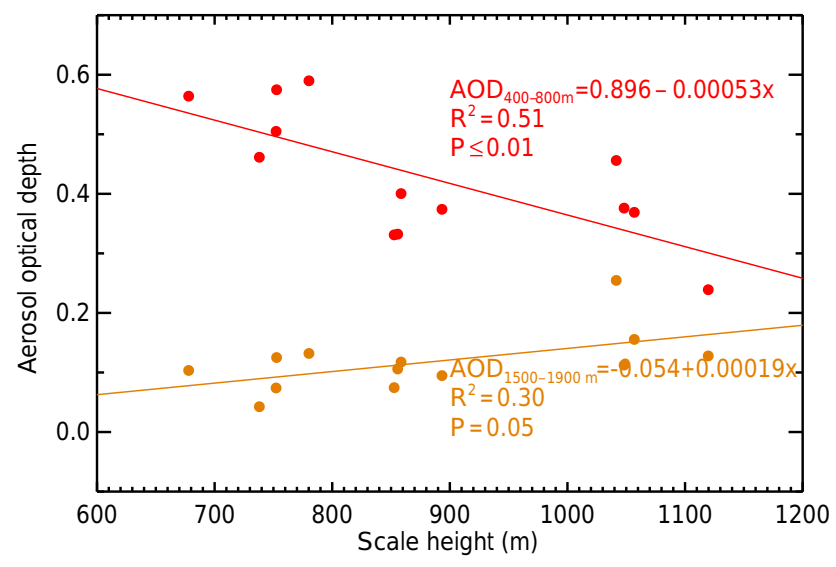

Figure 7. $A O D$ in the lower PBL $\left(\mathrm{AOD}_{400-800 \mathrm{~m}}\right)$ and in the upper PBL (AOD $1500-1900 \mathrm{~m})$ as a function of aerosol scale height. Linear-fit equations, coefficients of determination, and $p$ values are given.

that of the ascending tendency over the entirety of China $(+0.0003)$ during the same period (He et al., 2016), suggesting that the changes in AOD at higher altitudes over the GZP are different from the changes in other regions. For the period 2008-2014, the trends in AOD at different altitudes are opposite to those from the 2002-2008 period. The AOD over the lowlands with altitudes $<700 \mathrm{~m}$ dramatically decreased while AOD at altitudes from 800 to $1200 \mathrm{~m}$ increased. To further illustrate this phenomenon, the variation in aerosol extinction coefficient derived from $\mathrm{d}(\mathrm{AOD}) / \mathrm{d} z$ using MODIS AOD retrievals in conjunction with the GDEM is shown in Fig. 8b. Concurrent with the increase in aerosol concentration in the lower PBL during the period 2002-2008, aerosol extinction coefficients at altitudes above $1850 \mathrm{~m}$ decreased with a maximum value occurring near $2300 \mathrm{~m}$. The opposite is seen during the period 2008-2014. A notable downward tendency in the aerosol extinction coefficient in the lower PBL is found, while at the same time a positive trend with a maximum magnitude of $0.04 \mathrm{~km}^{-1} \mathrm{yr}^{-1}$ is seen at altitudes between 900 and $1300 \mathrm{~m}$. The vertical distribution of trends in AOD and aerosol extinction coefficient during the two periods show that changes in aerosol loading near the surface were opposite to those above the PBLH over the GZP, which is solid evidence that the aerosol-PBL feedback plays a significant role in the long-term trend in air pollution and especially in the opposite trends between the lower and upper PBL.

To further investigate the role of aerosol absorption in the opposite trends, we expanded our satellite analyses to over large areas in China containing aerosols with a different light-absorbing property. The SSA in northern China is generally lower than in southern China (Lee et al., 2007). It was thus hypothesized that the reversal trends in northern China would be more significant than in southern China, which is 

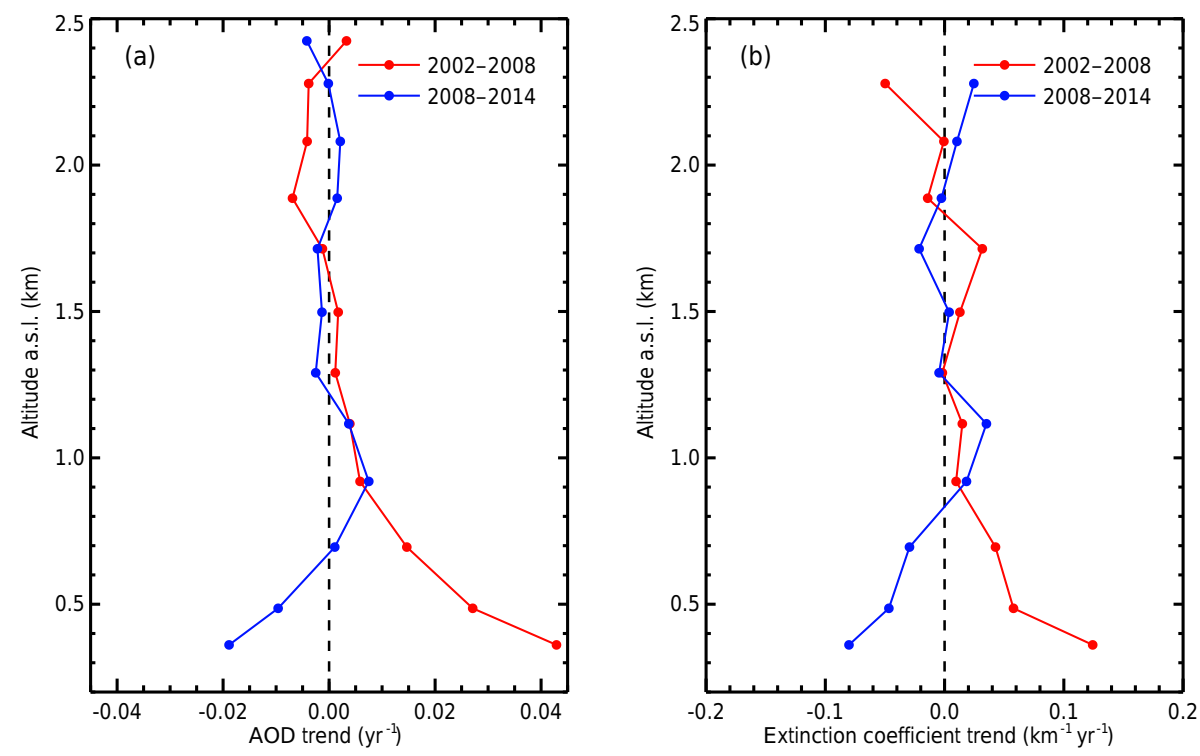

Figure 8. Vertical distributions of trends in summertime mean (a) AOD and (b) aerosol extinction coefficient. The vertical resolution is $200 \mathrm{~m}$. Red and blue lines represent tendencies during the period 2002-2008 and 2008-2014, respectively. The "a.s.l." in the ordinate labels stands for "above sea level".

confirmed from the trend analyses at different altitudes over the entire period of MODIS observations shown in Fig. 9.

Even though the MODIS AOD retrievals are relatively limited in winter due to the bright surface, the trend in AOD at different altitudes over the entirety of China is examined as well. As shown in Fig. 10, the profile of AOD trends at different altitudes in winter is similar to that in summer (Fig. 3a). The major difference between the two is that the transition from negative to positive values in AOD trends takes place at a lower altitude. This is because the PBL height is generally lower in winter than in summer (Guo et al., 2016). Moreover, the transition zone in the long-term trends in surface visibility over the GZP shows a downward shift as well (not shown here). This finding confirms that the aerosol-PBL feedback plays a more important role in winter.

\section{Summary and conclusions}

An aerosol and PBL interaction has been speculated, chiefly based on an inverse correlation between air pollution (both gas and particulate pollutants) and PBL height. This may not be construed as evidence of the interaction because they may co-vary with meteorological conditions. A low PBL is favorable for the accumulation of any pollutant, but this does not imply that they interact with each other. For aerosols to interact with the PBL, the atmospheric thermodynamic status must be modified.

To obtain more direct evidence and to gain further insight into the interaction on both air pollution and PBL dynamics, we took advantage of rich measurements made from an intensive field experiment, long-term routine surface visibility observations, and satellite-based aerosol retrievals. A unique region in central China was chosen: the GZP and the Qinling mountain range composed of mountains having a wide range of heights. The GZP is one of the most heavily polluted regions in China due to coal-burning industries and has the lowest aerosol SSA measured in China. Next to the GZP lies the Qinling mountain range, which offers an opportunity to examine vertical profiles of aerosol loading through a novel method proposed here.

Using both the inferred and observed profiles of aerosol extinction together with computations of aerosol-induced radiative heating, a unique "signature" of the interaction between absorbing aerosols and the PBL is discovered, namely, the opposite trends in aerosol extinction, visibility, and aerosol optical depth as measured in the lower and upper PBL. Visibility data collected at meteorological stations located at altitudes below and above $1 \mathrm{~km}$ showed generally downward and upward trends, respectively, since 1980. The same opposite trends are also seen from retrievals of AOD from both MODIS and MISR since $\sim 2000$ over regions with altitudes below and above $1 \mathrm{~km}$. Two years of lidar measurements showed that the vertical structure of the aerosol extinction coefficient varied systematically with the aerosol concentration in the lower atmosphere; i.e., a cleaner atmosphere near the surface corresponded to a higher peak in aerosol extinction in the upper PBL and vice versa. As near-surface pollutants accumulate, they are confined to the lower PBL due to enhanced atmospheric stability, whereas pollutants in the upper PBL are dispersed more efficiently as the atmosphere becomes more unstable, thanks to heating in the lower PBL. 

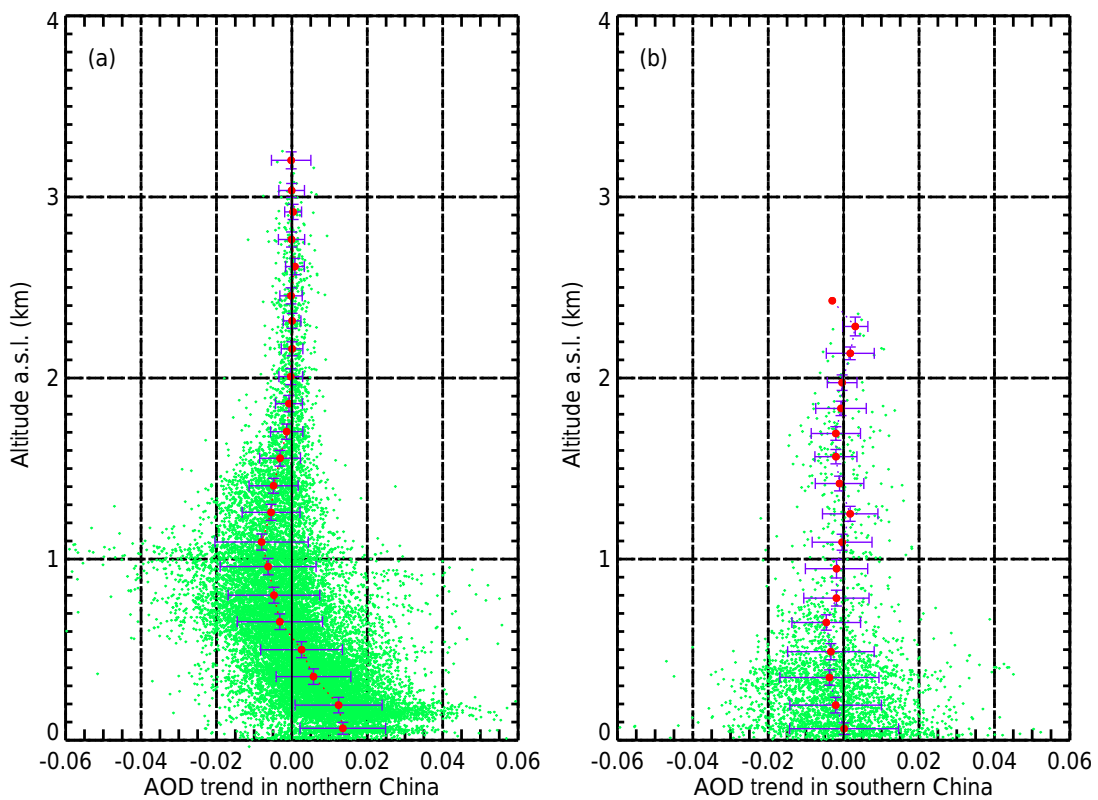

Figure 9. Vertical distributions of the trend in AOD from MODIS-Aqua in (a) northern $\left(>40^{\circ} \mathrm{N}\right)$ and $(\mathbf{b})$ southern $\left(<30^{\circ} \mathrm{N}\right)$ China from 2002 to 2014. The specific region of study can be found in Fig. S3.

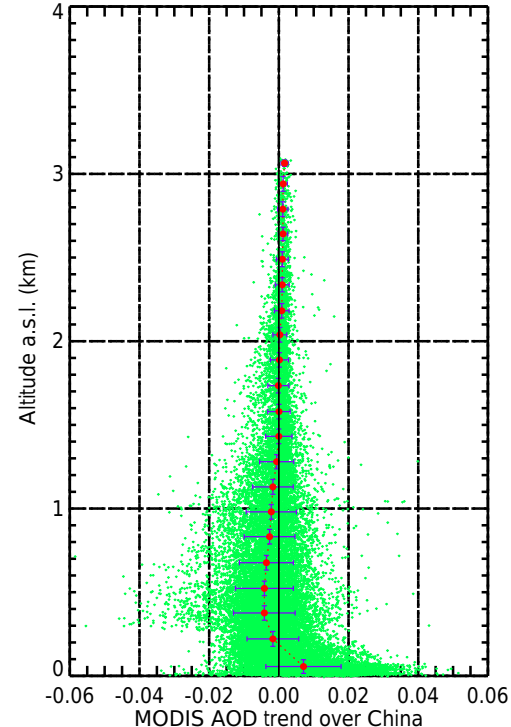

Figure 10. Vertical profiles of the trend in aerosol optical depth (AOD) from MODIS-Aqua in the winter seasons of 2002 to 2014 over the entirety of China. The "a.s.l" in the ordinate labels stands for "above sea level".

To further verify if it indeed stems from aerosol-PBL interactions, similar analyses were done in regions with distinctly different values of SSA. In low SSA regions, the reversal trends are much more pronounced than in high SSA regions, which attests to the critical role of aerosol absorption.
The findings presented in this study have numerous important implications. First, they signify the importance of aerosol-PBL interactions in dictating ground-level pollution. In particular, they imply that particulate pollution at the ground level can be much heavier than what is denoted by a column-integrated AOD. The latter is relatively readily and widely available and has been used as a proxy for indices representing air pollution on the ground such as $\mathrm{PM}_{2.5}$ and $\mathrm{PM}_{10}$. In regions/periods dominated by absorbing aerosols, changes in AOD may be totally decoupled from ground-level PM concentrations. Second, the findings suggest that one may not be able to use ground-based measurements of pollutants to assess the effect of any emission controls. Taking China as an example, drastic measures have been taken to reduce emissions but they seem to have little impact on heavy haze episodes because a significant part of the real reduction may have occurred in the upper PBL at the expense of worsening air quality at the surface or lower atmosphere. Finally, the findings point to a more efficient means of reducing air pollution: reducing/removing absorbing aerosols such as soot or black carbon, which can cause far more serious pollution than non-absorbing aerosols such as sulfates.

Data availability. The ASTER GDEM and MODIS AOD data are available from http://reverb.echo.nasa.gov/reverb and https:// ladsweb.nascom.nasa.gov/, respectively. The MPL-derived aerosol profiles and other relevant data are available upon request (contact: Zipeng Dong, dzp2003@126.com). 


\section{The Supplement related to this article is available online at https://doi.org/10.5194/acp-17-7997-2017-supplement.}

Competing interests. The authors declare that they have no conflict of interest.

Acknowledgements. This work was supported by the National Natural Science Foundation of China (91544217, 41675141, 41375155), the National Basic Research Program (973 Program) of China (2013CB955804), the joint National Natural Science Foundation of China and Israel Science Foundation research program (41561144004), and the National Natural Science Foundation of US (AGS-1337599). We thank NASA for providing ASTER GDEM and MODIS AOD data.

Edited by: Renyi Zhang

Reviewed by: two anonymous referees

\section{References}

Alexandrov, M. D., Marshak, A., Cairns, B., Lacis, A. A., and Carlson, B. E.: Automated cloud screening algorithm for MFRSR data, Geophys. Res. Lett., 31, L04118, https://doi.org/10.1029/2003GL019105, 2004.

Barbaro, E., Arellano, V. G., Krol, M. C., and Holtslag, A. A.: Impacts of aerosol shortwave radiation absorption on the dynamics of an idealized convective atmospheric boundary layer, BoundLay. Meteorol., 148, 31-49, https://doi.org/10.1007/s 10546-0139800-7, 2013.

Che, H., Zhang, X.-Y., Xia, X., Goloub, P., Holben, B., Zhao, H., Wang, Y., Zhang, X.-C., Wang, H., Blarel, L., Damiri, B., Zhang, R., Deng, X., Ma, Y., Wang, T., Geng, F., Qi, B., Zhu, J., Yu, J., Chen, Q., and Shi, G.: Ground-based aerosol climatology of China: aerosol optical depths from the China Aerosol Remote Sensing Network (CARSNET) 2002-2013, Atmos. Chem. Phys., 15, 7619-7652, https://doi.org/10.5194/acp15-7619-2015, 2015.

Chen, H. and Wang, H.: Haze days in North China and the associated atmospheric circulations based on daily visibility data from 1960 to 2012, J. Geophys. Res.-Atmos., 120, 5895-5909, https://doi.org/10.1002/2015jd023225, 2015.

Chen, Y., Ebenstein, A., Greenstone, M., and Li, H. B.: Evidence on the impact of sustained exposure to air pollution on life expectancy from China's Huai River policy, P. Natl. Acad. Sci. USA, 110, 12936-12941, https://doi.org/10.1073/pnas.1300018110, 2013.

Ding, A. J., Fu, C. B., Yang, X. Q., Sun, J. N., Petäjä, T., Kerminen, V.-M., Wang, T., Xie, Y., Herrmann, E., Zheng, L. F., Nie, W., Liu, Q., Wei, X. L., and Kulmala, M.: Intense atmospheric pollution modifies weather: a case of mixed biomass burning with fossil fuel combustion pollution in eastern China, Atmos. Chem. Phys., 13, 10545-10554, https://doi.org/10.5194/acp-13-105452013, 2013.

Ding, A. J., Huang, X., Nie, W., Sun, J. N., Kerminen, V. M., Peteja, T., Su, H., Cheng, Y. F., Yang, X. Q., Wang, M. H., Chi,
X. G., Wang, J. P., Virkkula, A., Guo, W. D., Yuan, J., Wang, S. Y., Zhang, R. J., Wu, Y. F., Song, Y., Zhu, T., Zilitinkevich, S., Kulmala, M., and Fu, C. B.: Enhanced haze pollution by black carbon in megacities in China, Geophys. Res. Lett., 43, 28732879, https://doi.org/10.1002/2016gl067745, 2016.

Ding, Y. H. and Liu, Y. J.: Analysis of long-term variations of fog and haze in China in recent 50 years and their relations with atmospheric humidity, Sci. China Ser. D, 57, 36-46, https://doi.org/10.1007/s11430-013-4792-1, 2014.

Dong, Z. P., Yu, X., Li, X. M., and Dai, J.: Analysis of variation trends and causes of aerosol optical depth in Shaanxi Province using MODIS data, Chinese Sci. Bull., 58, 4486-4496, https://doi.org/10.1007/s11434-013-5991-z, 2013.

Fan, J. W., Zhang, R. Y., Tao, W. K., and Mohr, K. I.: Effects of aerosol optical properties on deep convective clouds and radiative forcing, J. Geophys. Res., 113, D08209, https://doi.org/10.1029/2007JD009257, 2008.

Fan, J. W., Rosenfeld, D., Yang, Y., Zhao, C., Leung, L. R., and Li, Z. Q.: Substantial contribution of anthropogenic air pollution to catastrophic floods in Southwest China, Geophys. Res. Lett., 42, 6066-6075, https://doi.org/10.1002/2015gl064479, 2015.

Gerasopoulos, E., Andreae, M. O., Zerefos, C. S., Andreae, T. W., Balis, D., Formenti, P., Merlet, P., Amiridis, V., and Papastefanou, C.: Climatological aspects of aerosol optical properties in Northern Greece, Atmos. Chem. Phys., 3, 2025-2041, https://doi.org/10.5194/acp-3-2025-2003, 2003.

Gonçalves, W. A., Machado, L. A. T., and Kirstetter, P.-E.: Influence of biomass aerosol on precipitation over the Central Amazon: an observational study, Atmos. Chem. Phys., 15, 6789-6800, https://doi.org/10.5194/acp-15-6789-2015, 2015.

Guo, J., Miao, Y., Zhang, Y., Liu, H., Li, Z., Zhang, W., He, J., Lou, M., Yan, Y., Bian, L., and Zhai, P.: The climatology of planetary boundary layer height in China derived from radiosonde and reanalysis data, Atmos. Chem. Phys., 16, 13309-13319, https://doi.org/10.5194/acp-16-13309-2016, 2016.

Guo, J. P., Su, T. N., Li, Z. Q., Miao, Y. C., Li, J., Liu, H., Xu, H., Cribb, M., and Zhai, P. M.: Declining summertime local-scale precipitation over eastern China from 1970 to 2010 and its potential link to aerosols, Geophys. Res. Lett., https://doi.org/10.1002/2017GL073533, online first, 2017.

Guo, S., Hu, M., Zamora, M. L., Peng, J. F., Shang, D. J., Zheng, J., Du, Z. F., Wu, Z. J., Shao, M., Zeng, L. M., Molina, M. J., and Zhang, R. Y.: Elucidating severe urban haze formation in China, P. Natl. Acad. Sci. USA, 111, 17373-17378, https://doi.org/10.1073/pnas.1419604111, 2014.

He, Q., Zhang, M., and Huang, B.: Spatio-temporal variation and impact factors analysis of satellite-based aerosol optical depth over China from 2002 to 2015, Atmos. Environ., 129, 79-90, https://doi.org/10.1016/j.atmosenv.2016.01.002, 2016.

Huang, R. J., Zhang, Y., Bozzetti, C., Ho, K. F., Cao, J. J., Han, Y. M., Daellenbach, K. R., Slowik, J. G., Platt, S. M., Canonaco, F., Zotter, P., Wolf, R., Pieber, S. M., Bruns, E. A., Crippa, M., Ciarelli, G., Piazzalunga, A., Schwikowski, M., Abbaszade, G., Schnelle-Kreis, J., Zimmermann, R., An, Z. S., Szidat, S., Baltensperger, U., Haddad, I. E., and Prévôt, A. S.: High secondary aerosol contribution to particulate pollution during haze events in China, Nature, 514, 218-222, https://doi.org/10.1038/nature13774, 2014. 
Khalizov, A. F., Xue, H. X., Wang, L., Zheng, J., and Zhang, R. Y.: Enhanced light absorption and scattering by carbon soot aerosol internally mixed with sulfuric acid, J. Phys. Chem. A, 113, 10661074, https://doi.org/10.1021/jp807531n, 2009.

Lau, K. M. and Kim, K. M.: Observational relationships between aerosol and Asian monsoon rainfall, and circulation, Geophys. Res. Lett., 33, L21810, https://doi.org/10.1029/2006g1027546, 2006.

Lee, K. and Chung, C. E.: Observationally-constrained estimates of global fine-mode AOD, Atmos. Chem. Phys., 13, 2907-2921, https://doi.org/10.5194/acp-13-2907-2013, 2013.

Lee, K. H., Li, Z., Wong, M. S., Xin, J. Y., Wang, Y. S., Hao, W. M., and Zhao, F. S.: Aerosol single scattering albedo estimated across China from a combination of ground and satellite measurements, J. Geophys. Res.-Atmos., 112, D22S15, https://doi.org/10.1029/2007jd009077, 2007.

Li, L. and Wang, Y.: What drives the aerosol distribution in Guangdong-the most developed province in Southern China?, Sci. Rep., 4, 5972, https://doi.org/10.1038/srep05972, 2014.

Li, Z., Lau, W. K., Ramanathan, V., Wu, G., Ding, Y., Manoj, M. G., Liu, J., Qian, Y., Li, J., Zhou, T., Fan, J., Rosenfeld, D., Ming, Y., Wang, Y., Huang, J., Wang, B., Xu, X., Lee, S. S., Cribb, M., Zhang, F., Yang, X., Takemura, T., Wang, K., Xia, X., Yin, Y., Zhang, H., Guo, J., Zhai, P. M., Sugimoto, N., Babu, S. S., and Brasseur, G. P.: Aerosol and monsoon climate interactions over Asia, Rev. Geophys., 54, 866-929, https://doi.org/10.1002/2015rg000500, 2016.

Li, Z. Q., Lee, K. H., Wang, Y. S., Xin, J. Y., and Hao, W. M.: First observation-based estimates of cloud-free aerosol radiative forcing across China, J. Geophys. Res., 115, d00k18, https://doi.org/10.1029/2009JD013306, 2010.

Lin, J. T., Pan, D., and Zhang, R. X.: Trend and interannual variability of Chinese air pollution since 2000 in association with socioeconomic development: a brief overview, Atmos. Ocean. Sci. Lett., 6, 84-89, 2013.

Peng, J. F., Hu, M., Guo, S., Du, Z. F., Zheng, J., Shang, D. J., Zamora, M. L., Zeng, L. M., Shao, M., Wu, Y. S., Zheng, J., Wang, Y., Glen, C. R., Collins, D. R., Molina, M. J., and Zhang, R. Y.: Markedly enhanced absorption and direct radiative forcing of black carbon under polluted urban environments, P. Natl. Acad. Sci. USA, 113, 4266-4271, https://doi.org/10.1073/pnas.1602310113, 2016.

Ricchiazzi, P., Yang, S., Gautier, C., and Sowle, D.: SBDART: A research and teaching software tool for planeparallel radiative transfer in the Earth's atmosphere, B. Am. Meteorol. Soc., 79, 2101-2114, https://doi.org/10.1175/15200477(1998)079<2101:SARATS>2.0.CO;2, 1998.

Song, G. N., Yang, X. Y., and Fu, J. P.: Aerosol optical parameter observations in Lanzhou City, J. Lanzhou University (Natural Sciences), 49, 470-483, https://doi.org/10.13885/j.issn.04552059.2013.04.004, 2013 (in Chinese).

Tesfaye, M., Botai, J., Sivakumar, V., and Tsidu, G. M.: Simulation of biomass burning aerosols mass distributions and their direct and semi-direct effects over south africa using a regional climate model, Meteorol. Atmos. Phys., 125, 177-195, https://doi.org/10.1007/s00703-014-0328-2, 2014.

Wang, G. H., Zhang, R. Y., Gomez, M. E., Yang, L. X., Zamora, M. L., Hu, M., Lin, Y., Peng, J. F., Guo, S., Meng, J. J., Li, J. J., Cheng, C. L., Hu, T. F., Ren, Y. Q., Wang, Y. S., Gao, J.,
Cao, J. J., An, Z. S., Zhou, W. J., Li, G. H., Wang, J. Y., Tian, P. F., Marrero, M., Secrest, J., Du, Z. F., Shang, D. J., Zeng, L. M., Shao, M., Wang, W. G., Huang, Y., Wang, Y., Zhu, Y. J., Li, Y. X., Hu, J. X., Pan, B. W., Cai, L., Cheng, Y. T., Ji, Y. M., Zhang, F., Rosenfeld, D., Liss, P. S., Duce, R. A., Kolb, C. E., and Molina, M. J.: Persistent sulfate formation from London Fog to Chinese haze, P. Natl. Acad. Sci. USA, 113, 13630-13635, https://doi.org/10.1073/pnas.1616540113, 2016.

Wang, H. J., Chen, H. P., and Liu, J.: Arctic sea ice decline intensified haze pollution in eastern China, Atmos. Ocean. Sci. Lett., 8, 1-9, https://doi.org/10.3878/aos120140081, 2015.

Wang, Y., Wan, Q., Meng, W., Liao, F., Tan, H., and Zhang, R.: Long-term impacts of aerosols on precipitation and lightning over the Pearl River Delta megacity area in China, Atmos. Chem. Phys., 11, 12421-12436, https://doi.org/10.5194/acp-11-124212011, 2011.

Wang, Y., Khalizov, A., Levy, M., and Zhang, R.: New directions: light absorbing aerosols and their atmospheric impacts, Atmos. Environ., 81, 713-715, https://doi.org/10.1016/j.atmosenv.2013.09.034, 2013.

Wang, Y. Q., Zhang, X. Y., Sun, J. Y., Zhang, X. C., Che, H. Z., and Li, Y.: Spatial and temporal variations of the concentrations of $\mathrm{PM}_{10}, \mathrm{PM}_{2.5}$ and $\mathrm{PM}_{1}$ in China, Atmos. Chem. Phys., 15, 13585-13598, https://doi.org/10.5194/acp-15-135852015, 2015.

Welton, E. J., Voss, K. J., Gordon, H. R., Maring, H., Smirnov, A., Holben, B., Schmid, B., Livingston, J. M., Russell, P. B., Durkee, P. A., Formenti, P., and Andreae, M. O.: Ground-based lidar measurements of aerosols during ACE2: instrument description, results, and comparisons with other ground-based and airborne measurements, Tellus, 52, 636-651, https://doi.org/10.1034/j.1600-0889.2000.00025.x, 2000.

Wendisch M., Hellmuth, O., Ansmann, A., Heintzenberg, J., Engelmann, R., Althausen, D., Eichler, H., Müller, D., Hu, M., Zhang, Y., and Mao, J.: Radiative and dynamic effects of absorbing aerosol particles over the Pearl River Delta, China, Atmos. Environ., 42, 6405-6416, https://doi.org/10.1016/j.atmosenv.2008.02.033, 2008.

Wu, G. X., Li, Z. Q., Fu, C. B., Zhang, X. Y., Zhang, R. Y., Zhang, R. H., Zhou, T. J., Li, J. P., Li, J. D., Zhou, D. G., Wu, L., Zhou, L. T., He, B., and Huang, R. H.: Advances in studying interactions between aerosols and monsoon in China, Sci. China Ser. D, 59, 1-16, https://doi.org/10.1007/s11430-015-5198-z, 2016.

Xia, X. A., Li, Z. Q., Holben, B., Wang, P. C., Eck, T., Chen, H. B., Cribb, M., and Zhao, Y. X.: Aerosol optical properties and radiative effects in the Yangtze Delta region of China, J. Geophys. Res., 112, d22s12, https://doi.org/10.1029/2007JD008859, 2007.

Yin, P., Brauer, M., Cohen, A., Burnett, R., Liu, J. M., Liu, Y. N., and Zhou, M. G.: Ambient fine particulate matter exposure and cardiovascular mortality in China: a prospective cohort study, Lancet, 386, 6-6, https://doi.org/10.1016/S01406736(15)00584-X, 2015.

Zhang, J. and Reid, J. S.: A decadal regional and global trend analysis of the aerosol optical depth using a data-assimilation grade over-water MODIS and Level 2 MISR aerosol products, Atmos. Chem. Phys., 10, 10949-10963, https://doi.org/10.5194/acp-1010949-2010, 2010.

Zhang, R. Y., Khalizov, A. F., Pagels, J., Zhang, D., Xue, H. X., and McMurry, P. H.: Variability in morphology, hygro- 
scopicity, and optical properties of soot aerosols during atmospheric processing, P. Natl. Acad. Sci. USA, 105, 10291-10296, https://doi.org/10.1073/pnas.0804860105, 2008.

Zhang, R. Y., Wang, G. H., Guo, S., Zamora, M. L., Ying, Q., Lin, Y., Wang, W. G., Hu, M., and Wang, Y.: Formation of Urban Fine Particulate Matter, Chem. Rev., 115, 3803-3855, https://doi.org/10.1021/acs.chemrev.5b00067, 2015.

Zhang, Y., Fu, R., Yu, H. B., Dickinson, R. E., Juarez, R. N., Chin, M., and Wang, H.: A regional climate model study of how biomass burning aerosol impacts land-atmosphere interactions over the Amazon, J. Geophys. Res.-Atmos., 113, d14s15, https://doi.org/10.1029/2007jd009449, 2008.
Zhao, S., Tie, X., Cao, J., and Zhang, Q.: Impacts of mountains on black carbon aerosol under different synoptic meteorology conditions in the Guanzhong region, China, Atmos. Res., 164, 286296, https://doi.org/10.1016/j.atmosres.2015.05.016, 2015a.

Zhao, S., Tie, X., Cao, J., Li, N., Li, G. H., Zhang, Q., Zhu, C. S., Long, X., Li, J. D., Feng, T., and Su, X. L.: Seasonal variation and four-year trend of black carbon in the Mid-west China: the analysis of the ambient measurement and WRF-Chem modeling, Atmos. Environ., 123, 430-439, https://doi.org/10.1016/j.atmosenv.2015.05.008, 2015b. 